\title{
Effect of Acidic Challenge Preceded by Food Consumption on Enamel Erosion
}

\author{
Heitor Marques Honórioa \\ Daniela Rios ${ }^{b}$ \\ Edmêr Silvestre Pereira Júniora \\ Daniela Silva Barroso de Oliveira ${ }^{a}$ \\ Fernanda Alves Fiora \\ Marília Afonso Rabelo Buzalaf ${ }^{c}$
}

\begin{abstract}
Objectives: This in vitro study aimed to evaluate the effect of food consumption followed by acidic challenge on enamel erosion.

Methods: Seventy-five enamel blocks obtained from bovine teeth were divided randomly into five groups ( $n=15$ per group): $\mathrm{GI}$ - erosion with previous immersion in milk; GII - erosion with previous immersion in cheese extract; GIII - erosion with previous immersion in liver extract; GIV - erosion with previous immersion in broccoli extract; and GV - erosive effect of cola drink (control). Over $24 \mathrm{~h}$, the slabs were submitted to $3 \mathrm{pH}$-cycles, each consisting of immersion in the studied food (GI to GIV) for $5 \mathrm{~min}$ followed by immersion in a cola drink for $5 \mathrm{~min}$, and subsequently, the slabs were stored in artificial saliva $(110 \mathrm{~min})$. At the end of the $\mathrm{pH}$-cycles, the slabs were stored in artificial saliva for $18 \mathrm{~h}$. Enamel alterations were assessed by profilometry $(\mu \mathrm{m})$. Data were tested using ANOVA and Scott-Knott's tests $(P<.05)$.

Results: Mean erosion depths for enamel ( $\mu \mathrm{m})$ were 0.46 in GI, 0.55 in GII, 0.64 in GIII, 0.54 in GIV, and 1.18 in GVI. Enamel loss by acidic challenge alone (GV) was significantly higher than when the acidic challenges were preceded by food extract immersion.

Conclusions: The data suggest that all studied foods could minimize the erosive effect on enamel. (Eur J Dent 2010;4:412-417)
\end{abstract}

Key words: Erosion; Dental wear; Enamel; in vitro.

Department of Pediatric Dentistry, Alfenas Federal University, Alfenas-MG, Brazil.

${ }^{b}$ Department of Pediatric Dentistry, Orthodontics and Public Health, Bauru School of Dentistry, USP University of São Paulo, Bauru-SP, Brazil. c Department of Biological Sciences, Bauru School of Dentistry, USP - University of São Paulo. Bauru-SP, Brazil.

- Corresponding author: Heitor Marques Honório Universidade Federal de Alfenas, Departamento de Clínica e Cirurgia (Disciplina de Odontopediatria), Rua Gabriel Monteiro da Silva, 714, Centro, Alfenas-MG, 37130-000 Brazil.

Phone: + 553532991424 Fax: + 553532926094

E-mail: heitorhonoriodyahoo.com.br

\section{INTRODUCTION}

The aetiology and prevalence of tooth wear have received increasing interest in the literature. ${ }^{1-4}$ Tooth wear has a multifactorial character; however, erosion has been found to be the main contributory factor, ${ }^{5,6}$ and there is a strong belief that attrition and abrasion are of lesser importance. ${ }^{7,8}$ Epidemiological studies have established that the prevalence of dental erosion is high in young people and adolescents..$^{911}$ One main goal in the management of dental erosion is the development of preventive strategies, which should be introduced at an early age. 
Dental erosion is the surface loss of tooth structure due to the action of acids without involvement of microorganisms. 5,12,13 Enamel exposed to acid loses minerals from a layer extending a few micrometres below the surface, a process known as softening. ${ }^{14}$ With time, as softening progresses further into the enamel, dissolution in the most superficial enamel will reach the point where this layer of enamel is lost completely. ${ }^{14}$ In vivo, erosion could, therefore, involve two types of enamel wear: the direct removal of hard tissue by complete dissolution and the creation of a thin softened layer, which is vulnerable to subsequent mechanical wear. ${ }^{14}$ Although a multitude of factors seem to be involved in this process, the most important factors are dietary acids ${ }^{15,16}$ and intrinsic acids from the stomach. ${ }^{17,18}$ Currently, the increased consumption of acidic foods and soft drinks is becoming an important factor in the development of erosive wear. ${ }^{15,16}$ On the other hand, the potential of dairy foods and drinks to protect teeth against dental erosion has been documented. ${ }^{19,20}$ Gedalia et $\mathrm{al}^{19}$ and Lewinstein et a ${ }^{20}$ showed the rehardening effects of cow's milk and cheese in situ following the softening of human enamel with an acidic soft drink (cola drink), and other studies have shown that milk and cheese rich in calcium. ${ }^{21,22}$ On the other hand, Kato, Sales-Peres and Buzalaf, ${ }^{23}$ and Kato et $\mathrm{al}^{24}$ have studied the role of iron in dental erosion, showing that this element may play an important role in preventing this alteration. Since liver is an important source of iron ${ }^{25}$ and broccoli is a vegetable very rich in this chemical element, ${ }^{26}$ these foods would also have an effect on dental erosion. The rehardening reported by the studies mentioned above refers to a reparative effect of the treatments after the erosion had been promoted. ${ }^{19,20}$ However, few studies have investigated the preventive effect of foods and drinks used before the erosive challenge.

Taking these considerations into account and considering that liver/broccoli and milk/cheese are foods rich in iron and calcium respectively, this in vitro study aimed to evaluate the effect of acidic challenge preceded by food consumption on enamel erosion.

\section{MATERIAL AND METHODS}

Enamel slab preparation

Seventy-five enamel slabs $(4 \times 4 \times 3 \mathrm{~mm})$ were prepared from extracted sound bovine incisors. One slab was cut from each crown using a lowspeed saw cutting machine (Isomet - Buehler Ltda., Lake Bluff, IL, USAl and two diamond disks (Extec Corp., Enfield, CT, USA) separated by a $4-\mathrm{mm}$ diameter spacer. The enamel surface was ground flat with water-cooled carborundum discs $\left(320,600\right.$, and 1200 grades of $\mathrm{Al}_{2} \mathrm{O}_{3}$ papers; Buehler, Lake Bluff, IL, USA) and polished with felt paper wet by diamond spray ( $1 \mu \mathrm{m}$; Buehler). This procedure resulted in the removal of about a 100 $\mu \mathrm{m}$ depth of enamel.

After the slab preparation, the surface microhardness was determined by making five indentations (Knoop diamond, 25 g, 5 s, HMV-2000; Shimadzu Corporation, Tokyo, Japan) for selection and randomized distribution. Enamel slabs with a microhardness ranging from 333 to $359 \mathrm{KHN}$ were distributed randomly into 5 groups $(n=15$, mean $344 \pm 7.6 \mathrm{KHN}$ ): $\mathrm{GI}$ - erosive effect of cola drink with previous immersion in milk; GII - erosive effect of cola drink with previous immersion in cheese extract; GIII - erosive effect of cola drink with previous immersion in liver extract; GIV - erosive effect of cola drink with previous immersion in broccoli extract, and GV - erosive effect of cola drink (control). Two layers of nail varnish were applied on half of the surface of the enamel in order to maintain reference surfaces for lesion depth determination.

\section{Preparation of food extracts and erosive $\mathrm{pH}$ -} cycling

Prior to the experiment, $250 \mathrm{~g}$ of each food (cheese, broccolis or liver) was triturated and diluted by $300 \mathrm{ml}$ of deionised water, resulting in a food extract. The cow milk was not diluted.

During $24 \mathrm{~h}$, the slabs from groups GI, GII, GIII and GIV were subjected to $3 \mathrm{pH}$-cycles $\left(37^{\circ} \mathrm{C}\right)$. In each cycle, the slabs were immersed in the studied food extract (GI to GIV) for 5 minutes ( $32 \mathrm{~mL}$ per slab) followed by immersion in a cola drink (CocaCola ${ }^{\circledR}$, Coca-Cola Company, Spal, Porto Real, RJ, Brazil) for 5 minutes ( $p H$ 2.6). The GV specimens (control group) in each cycle were immersed in artificial saliva for 5 minutes ( $\mathrm{pH} 7.0$ ) followed by immersion in a cola drink for 5 minutes. Between the erosive challenges, the slabs were immersed in artificial saliva [1.5 mM Ca( $\left.\mathrm{NO}_{3}\right)_{2} .4 \mathrm{H}_{2} \mathrm{O}, 0.9 \mathrm{mM}$ $\mathrm{NaH}_{2} \mathrm{PO}_{4} \cdot 2 \mathrm{H}_{2} \mathrm{O}, 150 \mathrm{mM} \mathrm{KCl}, 0.1 \mathrm{M}$ Tris buffer, 0.03 
ppm F, pH 7.0] for 110 minutes (32 $\mathrm{mL}$ per slab) at room temperature. At the end of the $\mathrm{pH}$-cycles, all slabs were stored in artificial saliva for $18 \mathrm{~h}$.

\section{Wear assessment}

After pH cycling, the nail varnish over the surfaces was cleaned carefully with acetone-soaked cotton. ${ }^{27}$ The enamel wear was determined profilometrically in relation to the reference surface (Hommel Tester T 1000, Hommelwerke, Schwenningen, Germany). ${ }^{28-30}$ The tracing parameters were established at Lt: $1.5 \mathrm{~mm}$ and Lc: $0.25 \mathrm{~mm}$ and the profilometry accuracy is $0.4 \mu \mathrm{m}$. Five readings were performed on each slab, and the average amount of wear was calculated. These profilometric traces were taken by moving the stylus from the reference surface to the exposed surface.

\section{Statistical analysis}

The assumptions of equality of variances and normal distribution of errors were checked. Since the assumptions were satisfied, ANOVA and ScottKnott's tests were carried out for statistical comparisons, and the significance limit was set at $5 \%$.

\section{RESULTS}

Table 1 shows the mean wear $(\mu \mathrm{m} \pm \mathrm{SD})$ of the groups (GI-GV). Enamel loss provoked by the cola drink (GV) was nearly 2-fold higher when compared to that observed when the acidic challenges were preceded by food extract immersion.

\section{DISCUSSION}

The present study was conducted in order to evaluate the dental enamel after an erosive challenge preceded by the consumption of daily used foods, which could cause the loss of dental structure.

For convenience, bovine enamel was used. Although a direct relationship between human and

Table 1. The mean wear profile $(\mu \mathrm{m})$ and standard deviation for the study groups.

\begin{tabular}{lcc}
\hline Groups & N & Wear $( \pm S d)^{*}$ \\
\hline GI - Milk & 15 & $0.46( \pm 0.17)^{\mathrm{a}}$ \\
GII - cheese & 15 & $0.55( \pm 0.22)^{\mathrm{a}}$ \\
GIII - liver & 15 & $0.64( \pm 0.19)^{\mathrm{a}}$ \\
GIV - broccoli & 15 & $0.54( \pm 0.19)^{\mathrm{a}}$ \\
GV - control & 15 & $1.18( \pm 0.40)^{\mathrm{b}}$ \\
\hline
\end{tabular}

*: Means followed by distinct letters are significantly different $(P<.05)$. bovine enamel for \%SMHC and wear was observed in a previous study, morphological differences such as higher porosity exist when compared to human enamel, which increases the formation of erosive lesions. ${ }^{28}$

Three $\mathrm{pH}$ cycles were chosen to simulate the consumption of erosive beverages and foods in the main meals (breakfast, lunch, and dinner). The artificial saliva used allows for rehardening of the slabs between the erosive challenges for simulation of the in vivo situation. ${ }^{31}$ However, under clinical conditions, human saliva is also responsible for the formation of the acquired pellicle, which is a physical barrier that protects the tooth against erosive attacks. ${ }^{32}$ This selective barrier prevents direct contact between acids and the tooth surface, thus reducing the dissolution of hydroxyapatite. Protection of the tooth surface by the acquired pellicle is well-established in the literature and has been demonstrated by several studies. ${ }^{33,34}$ In this in vitro study, there was no acquired pellicle formation, and the absence of this natural protection may have increased the erosive attack on the enamel slabs. In addition, under clinical conditions, the presence of a salivary pellicle might affect the adhesion of proteins on the enamel surface, increasing the protective effect of the studied foods.

In this study, enamel wear was used as response variable since it is able to measure the complete dental loss induced by the $\mathrm{pH}$-cycles, thus reflecting the cumulative effect of the erosive challenges. It has to be taken into consideration that in the contact profilometry, as done in the present study, the stylus might be able to scratch the acid-softened surface. ${ }^{35}$ However, even when the stylus might damage the surface to a small extent, it is assumed that this phenomenon can be observed in all groups and might not affect possible differences among the groups. The resolution of the profilometer is $0.4 \mu \mathrm{m}$, allowing highly precise wear measurement because the mean erosion depths of the studied groups were higher than the error limit of the equipment.

The results of the present study showed that the food contact previously to the erosive challenge minimized the enamel erosion. This data could be explained by the fat and/or protein content of the tested foods, which could have acted as a physical barrier, thus limiting the action of 
the acidic drink. ${ }^{36}$ Lewinstein et $\mathrm{al}^{20}$ hypothesized several mechanisms for caries inhibition by cheese: protection derived from bufferfat, buffering of dietary acids through metabolism of protein breakdown products, and prevention of demineralisation and/or promotion of remineralisation by casein, calcium lactate, ionisable calcium, and phosphate present in dairy foods. Taking these aspects into account, another hypothesis could be related to the calcium ( $\mathrm{Ca}$ ) present in the studied foods. In agreement with the present study, Weiss and Bibby ${ }^{37}$ showed that bovine enamel exposed previously to cow's milk was $20 \%$ less soluble in acetic acid than the control enamel.

Another ion that could enhance the protective effect of the foods (liver and broccoli) is iron (Fe). The mechanism involved in this protection of iron against mineral dissolution is not completely understood. It is possible that the formation of a thin acid-resistant coating of hydrous iron oxide on the enamel mineral surface may be a possible factor. ${ }^{38}$ It has been shown that when the enamel is incubated with solutions of ferric salts, acid-resistant enamel surfaces are established due to the precipitation of ferric phosphate on the surface of the enamel. ${ }^{38}$ The formation of this ferric phosphate barrier was also suggested in recent in situ studies, simulating situations of high cariogenic ${ }^{39}$ and erosive/abrasive challenges. ${ }^{40}$ The formation of such a of ferric phosphate barrier would reduce the contact of the soft drink with the enamel in subsequent acid challenges, which would, in turn, diminish the wear.

Prior studies have aimed to investigate the preventive effect of calcium and iron on dental erosion. However, these ions were added to commercial soft drinks or to pure acids. ${ }^{41,42}$ The present study more closely resembles the clinical situation, not only because of the presence of the ions in daily consumed foods or drinks but also because of the use of these ions in non-toxicological concentrations.

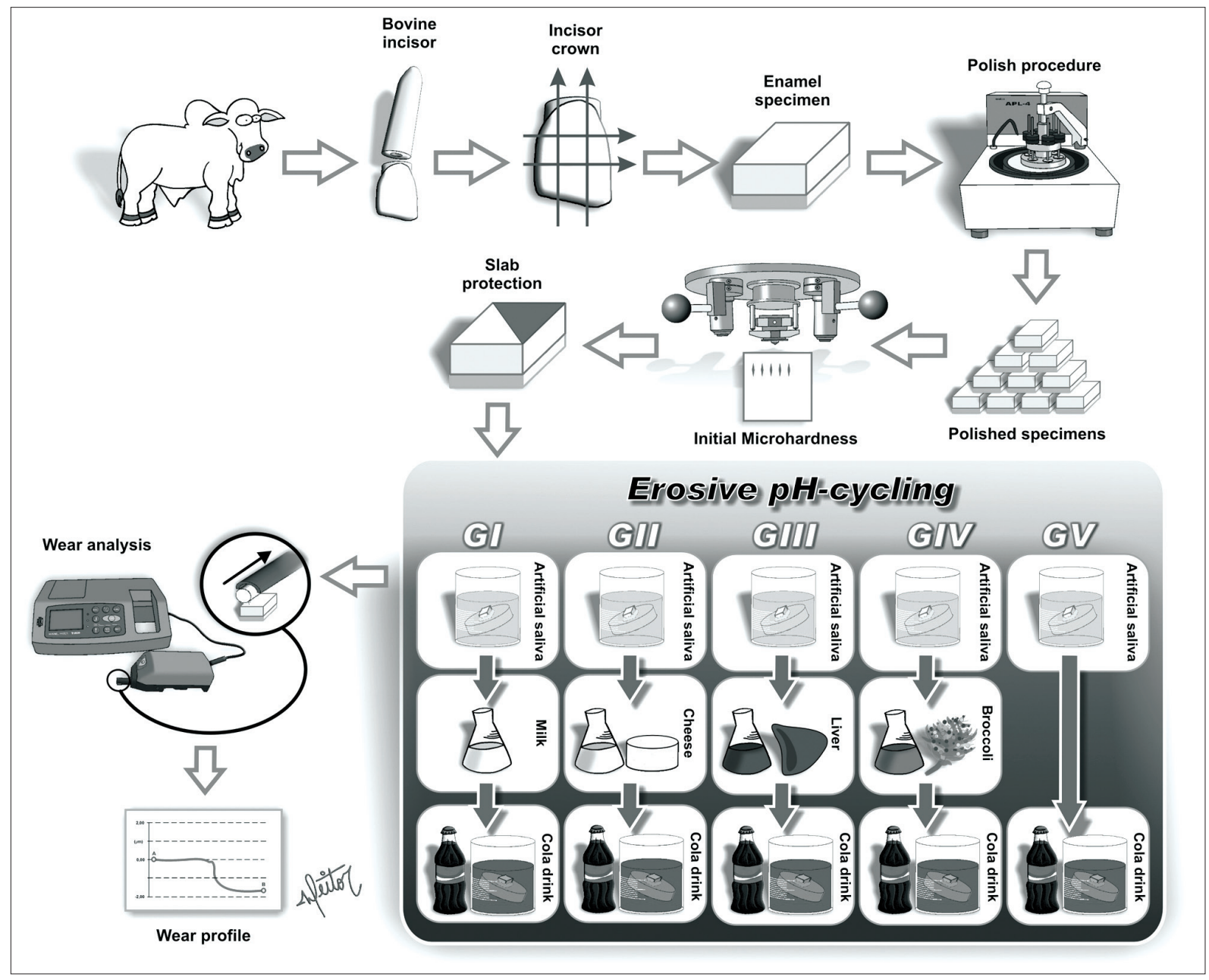

Figure 1. Schematic drawing of the experimental design. 


\section{CONCLUSIONS}

The results of the present in vitro study suggest that the tested foods, when consumed before erosive challenges, can significantly reduce the wear. The consumption of these foods before or with acidic beverages could be a good strategy to diminish the deleterious effect of the beverage, especially for patients at high risk to dental erosion due to excessive use of these beverages. Due to the limitations of this in vitro protocol, however, before this preventive measure can be widely recommended, histochemical analysis of the enamel is necessary, and the data should be confirmed by in situ and clinical studies.

\section{ACKNOWLEDGMENTS}

The authors would like to gratefully acknowledge Prof. Dr. Luiz Alberto Beijo for the statistical analysis. The study was supported by FAPEMIG (Research Support Foundation of Minas Gerais State).

\section{REFERENCES}

1. Johansson AK, Sorvari R, Birkhed D, Meurman JH. Dental erosion in deciduous teeth-an in vivo and in vitro study. $J$ Dent 2001;29:333-340.

2. Millward A, Shaw L, Smith AJ, Rippin JW, Harrington E. The distribution and severity of tooth wear and the relationship between erosion and dietary constituents in a group of children. Int J Paediatr Dent 1994;4:151-157.

3. Milosevic A, Young PJ, Lennon MA. The prevalence of tooth wear in 14-year old children in Liverpool. Community Dent Health 1994;11:83-86.

4. Rios D, Magalhães AC, Honório HM, Buzalaf MAR, Lauris, JRP, Machado MAAM. The prevalence of deciduous tooth wear in six-year-old children and its relationship with potential explanatory factors. Oral Health Prev Dent 2007;5:167-171.

5. Meurman JH, Ten Cate JM. Pathogenesis and modifying factors of dental erosion. Eur J Oral Sci 1996;104:199-206.

6. Millward A, Shaw L, Smith A. Dental erosion in four-yearold children from differing socioeconomic background. $J$ Dent Child 1994;61:263-266.

7. Smith BG, Roob ND. The prevalence of tooth wear in 1007 dental patients. J Oral Rehabil 1996;23:232-239.

8. Smith BG, Bartlett DW, Roob ND. The prevalence, etiology and management of tooth wear in the United Kingdom. $J$ Prosthet Dent 1997;78:367-372.
9. Nunn JH, Gordon PH, Morris AJ, Pine CM, Walker A. Dental erosion-changing prevalence? A review of British national childrens' surveys. Int J Paediatr Dent 2003;13:98-105.

10. Shaw L, Smith AJ. Dental erosion-the problem and some practical solutions. Br Dent J 1999;186:115-118.

11. Williams D, Croucher R, Marcenes W, O'Farrell M. The prevalence of dental erosion in the maxillary incisors of 14-year-old school children living in Tower Hamlets and Hackney, London UK. Int Dent J 1999;49:211-216.

12. Imfeld T. Prevention of progression of dental erosion by professional and individual prophylactic measures. Eur $J$ Oral Sci 1996;104:215-220.

13. Lussi A. Erosive tooth wear-a multifactorial condition of growing concern and increasing knowledge. Monogr Oral Sci 2006;20:1-8

14. Addy M, Shellis, RP. Interaction between attrition, abrasion and erosion in tooth wear. Monogr Oral Sci 2006;20:17-31.

15. Lussi A, Jaeggi T, Zero D. The role of diet in the etiology of dental erosion. Caries Res 2004;38:34-44.

16. Lussi A, Jaeggi T. Chemical factors. Monogr Oral Sci 2006;20:77-87.

17. Bartlett D. Intrinsic causes of erosion. Monogr Oral Sci 2006;20:119-139.

18. Scheutzel P. Etiology of dental erosion-intrinsic factors. Eur J Oral Sci 1996;104:178-190.

19. Gedalia I, Dakuar A, Shapira L, Lewinstein I, Goultschin J, Rahamim E. Enamel softening with coca-cola and rehardening with milk or saliva. Am J Dent 1991;4:120-122.

20. Lewinstein I, Ofek L, Gedalia I. Enamel rehardening by soft cheeses. Am J Dent 1993;6:46-48.

21. Nicklas TA. Calcium intake trends and health consequences from childhood through adulthood. J Am Coll Nutr 2003;22:340-356.

22. Durá Travé T. Intake of milk and dairy products in a college population. Nutr Hosp 2008;23:89-94.

23. Kato MT, Sales-Peres SH, Buzalaf MA. Effect of iron on acid demineralisation of bovine enamel blocks by a soft drink Arch Oral Biol 2007;52:1109-1111.

24. Kato MT, Italiani FM, Araújo JJ, Garcia MD, Sales-Peres $\mathrm{SH}$, Buzalaf MA. Preventive effect of an iron varnish on bovine enamel erosion in vitro. J Dent 2009;37:233-236.

25. Krebs NF. Food choices to meet nutritional needs of breast-fed infants and toddlers on mixed diets. $J$ Nutr 2007; 137:511S-517S.

26. Moreno DA, López-Berenguer C, García-Viguera C. Effects of stir-fry cooking with different edible oils on the phytochemical composition of broccoli. J Food Sci 2007;72:S064S068. 
27. Attin T, Buchalla W, Gollner M, Hellwig E. Use of variable remineralization periods to improve the abrasion resistance of previously eroded enamel. Caries Res 2000;34:4852.

28. Rios D, Honório HM, Magalhães AC, Delbem ACB, Machado MAAM, Silva SMB, Buzalaf MA. Effect of salivary stimulation on erosion of human and bovine enamel subjected or not to subsequent abrasion: an in situ/ex vivo study. Caries Res 2006;40:218-223.

29. Magalhães AC, Rios D, Delbem ACB, Buzalaf MAR, Machado MAAM. Influence of fluoride dentifrice on brushing abrasion of eroded human enamel: an in situ/ex vivo study. Caries Res 2007;41:77-79.

30. Honório HM, Rios D, Santos CF, Magalhães AC, Buzalaf MA, Machado MA. Effects of erosive, cariogenic or combined erosive/cariogenic challenges on human enamel: an in situ/ex vivo study. Caries Res 2008;42:454-459.

31. Vieira AEM, Delbem ACB, Sassaki KT, Rodrigues E, Cury $\mathrm{JA}$, Cunha RF. Fluoride dose response in $\mathrm{pH}$-cycling models using bovine enamel. Caries Res 2005;39:514-520.

32. Meurman JH, Frank RM. Scanning electron microscope of the effect of salivary pellicle on enamel erosion. Caries Res $1991 ; 25: 1-6$.

33. Hannig M, Balz M. Protective properties of salivary pellicles from two different intraoral sites on enamel erosion. Caries Res 2001;35:142-148.

34. Hannig M, Fiebiger M, Güntzer M, Döbert A, Zimehl R, NekrashevychY. Protective effect of the in situ formed short-term salivary pellicle. Arch Oral Biol 2004;49:903910.

35. Barbour ME, Rees JS. The laboratory assessment of enamel erosion: a review. J Dent 2004;32:591-602.

36. Hara AT, Lussi A, Zero DT. Biological Factors. Monogr Oral Sci 2006;20:88-99.

37. Weis ME, Bibby BG. Effects of milk on enamel solubility. Arch Oral Biol 1966;11:49-57.

38. Torell P. Iron and dental caries. Swed Dent J 1988;12:113124.

39. Martinhon CCR, Italiani FM, Padilha PM, Bijella MF, Delbem ACB, Buzalaf MAR. Effect of iron on bovine enamel and on the composition of the dental biofilm formed in situ. Arch Oral Biol 2006;51:471-475.

40. Sales-Peres SHC, Pessan JP, Buzalaf MAR. Effect of an iron mouthrinse on enamel and dentine erosion subjected or not to abrasion: an in situ/ex vivo study. Arch Oral Biol 2007;52:128-132.

41. Attin T, Meyer K, Hellwig E, Buchalla W, Lennon AM. Effect of mineral supplements to citric acid on enamel erosion. Arch Oral Biol 2003;48:753-759.
42. Goldhaber SB. Trace element risk assessment: essentiality vs. toxicity. Regul Toxic Pharma 2003;38:232-242. 